\title{
El urbanismo y la vivienda en Suecia
}

Suecia ofrece un paisaje atrayente y ameno debido al relieve del terreno, al verde de los prados, a la riqueza de los bosques y a los abundantes ríos y lagos; éstos alcanzan la cifra de 94.000 .

Tiene, en la actualidad, una población de 6,7 millones de habitantes, distribuídos sobre un territorio de 449.000 kilómetros cuadrados. Con tener una superficie sensiblemente menor que España, su densidad de población no pasa de 15 habitantes por kiiómetro cuadrado, es decir, aproximadamente la misma que los Estados Unidos.

Se cuentan en Suecia 128 ciudades, de las cuales 28 tienen una población superior a 20.000 habitantes, y de hecho el 48 por 100 de los habitantes del país viven en las ciudades. Tres de ellas son ciudades importantes: Estocolmo, la capital, que agrupa actualmente 725.000 almas; Gotenburgo, que tiene 344.000 , y Malmö, que sólo ạlcanza los 186.000 habitantes.

La industrialización, iniciada con retraso en Suecia, en el último cuarto del siglo pasado, provocó un movimiento del campo a la ciudad, y a ello se debe que, en tanto en setenta y cinco años la población sueca pasa de 4,2 a 6,7 millones, la población de los centros urbanos pasa del 13 por 100 al 48 por 100 de la población total del país. 
En Suecia se ha producido un gran desarrollo de los aglomerados urbanos, debido al incremento rápido de la población residente en las ciudades. Ello trajo consigo un problema de vivienda, cuya crisis coincidió con la primera guerra mundial. Es después de este momento que se adoptan medidas para salir al paso del problema.

La ayuda estatal, haciéndose intensa, logra entre 1940 y 1950 , la construcción en el país de 410.000 viviendas, récord, probableménte no igualado por otro estado europeo, si se tiene en cuenta la escasa población de Suecia.

Para lograr tal ritmo de construcción, usando de los recursos del Estado, del alto nivel económico del país y la euforia económica del decenio posterior a la segunda guerra, el Gobierno sueco eleva los préstamos para construcción de viviendas, en algunos casos hasta el 90 por 100 del valor de la construcción y aun ha concedido subvenciones especiales a las familias, con más de dos hijos, que habitan una vivienda de dos dormitorios y cocina, con calefacción central y baño, dándoles al efecto 130 coronas anuales por hijo; si tal subsidio no es suficiente, puede otorgárseles una reducción del 15 por 100 sobre la renta anual de la vivienda. Calculan que los próximos diez años, del 20 al 25 por 100 de las viviendas de nueva construcción en los centros urbanos podrán lograr este beneficio.

La política sueca de vivienda prevé una elevación progresiva - del "stándard" espacial en forma que las viviendas de un dormitorio no serán admitidas como hogares familiares, y asimismo que todos los alojamientos construídos o transformados con ayuda de fondos públicos han de tener calefacción central, agua, cloacas, cuarto de baño y cocinas bien equipadas.

Las condiciones y cuantía de la ayuda económica son distintas según los casos. En general, parece que sobre bloques plurifamiliares se otorgan préstamos base que devengan un interés del 3 por 100 y tienen un período de amortización de cincuenta años 
y, además, unos anticipos sin interés reintegrables a los diez años ; varía el detalle de la cosa, según sea la entidad constructora. Para viviendas unifamiliares se concedén préstamos de "propiedad privada" hasta el 90 por 100 y a un interés del 3 por 100 ; así como la denominada "subvención-capital" a fondo perdido que puede alcanzar del 10 por 100 al 20 por 100 de los gastos de construcción. Según parece, sólo en el presupuesto 1949-1950, los fondos públicos han dedicado 425 millones de coronas a la política de vivienda; de ellos, 300 eran préstamos y 150 anticipos o sůbvenciones.

A este respecto, parece que la construcción de viviendas alcanza en el país un precio por metro cuadrado y planta de 150 a 200 coronas, y para juzgar sobre tal cifra, diremos que el jornal mínimo es de 900 coronas al mes. Las entidades constructoras de viviendas pueden ser: cooperativas, sociedades autorizadas, Ayuntamientos o los propios interesados.

Aun en casas de pisos, la vivienda puede ser en alquiler o en amortización. En Västeras, por ejemplo, están construyendo un barrio de viviendas que ha de servir a las industrias eléctricas y metalúrgicas de la ciudad que cuenten con 10.000 obreros; dicho barrio contará con escuelas, campos de juego y deporte, parques, etcétera, y es construído por una empresa privada con apoyo estatal y municipal. Paga un interés del 3 por 100 del préstamo que le ha otorgado el Banco Oficial de la Construcción y cobran de alquiler el 7 por 100 del valor de la vivienda. En Lingköping es una cooperativa la que construye las viviendas, pagando los usuarios de amortización 1.800 coronas anuales. En Karlstad, una cooperativa construye un barrio de 3.000 viviendas aportando un 5 por 100 los beneficiarios y el 95 por 100 el Estado; pagarán de amortización 185 coronas mensuales por vivienda de tres dormitorios.

En algunos casos, los barrios de viviendas unifamiliares se construyen a base de una parcelación de terrenos urbanizados por d Ayuntamiento, que facilita el derecho de superficie por un plazo de sesenta años sobre lotes de unos 500 metros cuadrados a base de una cuota anual de 150 a 200 coronas. E! Estado facilita 
en tales casos hasta el 90 por 100 del importe de la obra, cuyo presupuesto, tratándose de casas pequeñas, viene a ser de unas 35.000 coronas por vivienda.

El sistema constructivo podemos decir que es el tradicional del país; la fábrica de bloques de hormigón o de ladrillo es normal en todas las casas plurifamiliares y en la mayor parte de las unifamiliares; algunas de estas últimas son construidas en madera, y en algunos casos se practica un revoque exterior sobre la propia madera. Siempre colocan aislante interior o exteror sobre la pared de 30 centímetros de espesor; suele ser aislante a base de fibra de madera.

En la vivienda se aprecia un perfecto acabado de todos los ramos, y llama la atención la calidad de las cocinas y sus instalaciones, las fregaderas de acero inoxidable, las cocinas eléctricas, las cámaras frigoríficas; magnífica la carpintería y los herrajes, y extraordinariamente resuelta, como en ningún otro país curopeo, la carpintería exterior de ventanas con doble cristal. Los suelos son en general de linoleum, y modernamente utilizan unas iosetas de material plástico.

La arquitectura no es, por lo general, muy lograda, aunque no faltan los bloques o conjuntos bien resueltos. El color es el elemento usado por los suecos para dar amenidad a sus construcciones, y en tal sentido procuran una variedad de colores en los interiores y en los elementos y asimismo una variedad en los distintos bloques de un conjunto. Los suecos tienen una intuición del paisaje y resuelvẹn magníficamente el dispositivo de los bloques y volúmenes de edificación dentro del conjunto urbano, amenizadio siempre por la introducción de la naturaleza en medio de la edificación. Las viviendas tienen calefacción y no les falta modernamente el servicio de ducha o baño. La calefacción es por bloques o por manzanas; también proporcionan a las viviendas servicios centrales de lavaderos mecánicos, guardería y parque infantil en cada unidad urbana. 
El abaratamiento de la construcción no se logra por fórmulas mágicas, sino por una normalización de los elementos: puertas, ventanas, cocinas, etc. En tal sentido, los suecos han logrado asimismo elevar el nivel estét:co del mobiliario gracias al trabajo conjunto de la Sociedad Sueca de Arte Aplicado (con cien años de existencia) con los industriales de distintos ramos. Se ha logrado normalizar un mobiliario moderno y confortable al alcance de todos los hogares.

Urbanísticamente, Suecia nos da muchas enseñanzas. El visitante queda sorprendido de que las revistas que llegan a nosotros queden cortas ante la magnitud de las realizaciones suecas. Los barrios concebidos con espíritu moderno no cuentan por unidades sino por centenares, y no sólo en las capitales, sino en todas las ciudades del país. La activa política de vivienda ha permitido, merced al nivel cultural y a la sensibilidad paisajistica de los suecos, crear conjuntos casi insuperables.

La vivienda unifamiliar se presenta en solución aislada y en solución continua. Dentro de esta última forma son modélicas las viviendas de Malmö, con su hábil disposición para lograr una intimidad de cada vivienda con relación a sus colindantes. Dentro de la solución plurifamiliar se adopta el tipo de casa-torre de ocho o diez plantas y cuatro viviendas por planta, de cuyo tipo fueron exponente los Punkthus del barrio de Danviksklippan en Estocolmo y las casas contiguas de tres plantas formando bioques de dos o tres escaleras, o incluso soluciones lineales retranqueadas de mayor número de escaleras, y de las que son una modalidad especial las casas estrelladas de Gröndal y de Orebrö.

En un principio, hasta la segunda guerra mundial adoptaron una ordenación rígida de bloques paralelos, pero después de esta segunda guerra se operó una evolución en las ideas y en los propósitos hacia un sistema más orgánico de la ciudad. Fruto de ello es la introducción de los "Community Centers" como foco de vida social de cada barrio y la disposición libre de los bloques 
dentro del conjunto de cada unidad urbana. Ni que decir tiene que resultan de una mayor simpatía los barrios dei último decenio, tanto en su plástica urbanística como en su dispositivo orgánico más en consonancia con nuestros sentimientos. El de Arsta es el único centro de comunidad terminado.

Cada unidad vecinal dispone de su jardín infantil y cada barrio tiene, asimismo, su guardería o su escuela. Cuando las guarderías son de pago, cobran unas tres coronas diarias por guardar ei niño. Los jardines infantiles disponen, en medio de un campo verde con masas de arbolado, de un lago de agua, otro de arena, columpios, toboganes, etc.

Recordemos que en 1947 dicta Suecia su Ley de Edificación (Ley que regula el uso del suelo y de la edificación, disponiendo la redacción de planes), pero ya antes, en 1945, Estocolmo había estudiado su Plan de Ordenación Urbana.

Estocolmo ha sufrido un aumento tal de población que ha doblado los habitantes del año 1920. Hoy tiene 725.000 habitantes, pero con su cinturón de poblados satélites (aunque municipios independientes), rebasa con mucho los 850.000, y se prevé para 1960 una población de 1.300 .000 almas en el Gran Estocolmo.

En su centro aparecen todos los problemas de las grandes ciudades: hacinamiento de población, congestión del tráfico, problemas de transporte y aun falta de solución urbanística brillante, de acuerdo con su categoría de gran ciudad. Sin duda, el cuarteamiento del territorio por los brazos de mar es una dificultad que viene a sumarse a las normales de cualquier capital. Por ello, el Plan de Ordenación de Estocolmo prevé como uno de sus puntos el saneamiento del núcleo central y de los antiguos ensanches construídos de acuerdo con el plano trazado por Lindhagen en la segunda mitad del siglo pasado. A pesar de que, normalmente, la altur:ı de los bloques no rebasa las cinco plantas, se alcanzan densidades de 1.200 personas por hectárea.

Mas no.se vaya a creer que por ello el antiguo ensanche de 
Estocolmo carece de espacios libres, bien al contrario, sin contan con los abundantes jardines de una hectárea de superficie, existen parques urbanos de cuatro a ocho hectáreas, separados unos 500 metros entre sí. Son, por ejemplo, Vanadis-lunden, Vasaparken, Observatorie-Junden, Humiegärden, Nobleparken, etcétera ; completados por los jardines y parques anejos a instituciones públicas o privadas: hospita'es, escuelas, castillos, museos, etc. Al lado de todo este programa, los grandes parques como Sadugärds, Gärdet, Skansen, Beckholmen, Sundbyberg, Haga, etc.

Afortunadamente, la falta de una especulación del suelo y probablemente el amor de los suecos hacia la naturaleza, ha evitado que el desarrollo urbano de los últimos treinta años se produjera en mancha de aceite y en forma de ensanches compactos; por el contrario, se ha atendido a una dispersión de los núcleos habitados y a la creación de un sistema de barrios satélites. Ello facilita la labor del Plan General, en cuanto se refiere a la ordenación del primero y segundo anillo.

Siguiendo tal trayectoria y a la vista de los problemas expuestos, el Plan de Estocolmo prevé la descongestión del centro; una red viaria con distinción clara de las arterias de tráfico, de las secundarias o de servicio a los barrios y las de tercer orden o de vivienda. Un plan de metros como desarrollo de la red actual y que permite la comunicación de los barrios satélites entre sí y con el centro y la creación de un sistema de poblados periféricos en cierta forma autosuficientes, es decir, constituídos cada uno de ellos cn esencia por el centro de comunidad, el núcleo central con casas de vecinos; los núcleos exteriores de habitación unifamiliar, las áreas de industria y los huertos familiares.

El principal atractivo de Estocolmo es la belleza de los barrios periféricos que sobrepasan en importancia y en extensión a los ensanches antiguos, con sus casas de vivienda de 3 a 10 plantas, constituyendo agrupaciones rodeadas de arbolado; con calles bien pavimentadas y limpios parques infantiles, parques urbanos, alfombras verdes, esculturas bien colocadas y habitantes aseados. Allí se comprueba que los barrios con edificación abierta y 
abundante espacio libre son una realidad posible y que en ellos se. vive mejor que en nuestras ciudades de piedra y asfalto.

Preciso es hacer constar que en Malmö, en Gotenburgo, en Västeras, en Karlstad, en Orebrö, en Lingköping, etc., podemos contemplar a la escala de cada ciudad idénticas realizaciones.

Los parques urbanos se hallan en todas las ciudades, tanto en ei centro como en los ensanches y lo construído de treinta años a esta parte, siempre es ciudad-jardín o ciudad verde, jugando ambas modalidades en provecho de un mejor servicio social y de una amenidad de los conjuntos urbanos.

La posibilidad de lograr a un tiempo la fácil solución al problema de la vivienda y un clima urbano moderno, se debe no tan sólo al nivel económico del país y al clima que facilita el desarrollo de la vegetación y del arbolado, sino también a tres condiciones que podemos hacer nuestras con voluntad: dirección urbanística, falta de especulación abusiva sobre el terreno y sentido del paisaje.

Los suecos, aun teniendo una sensibilidad artística probablemente inferior a la nuestra, logran magníficos conjuntos urbanos porque tienen una intuitiva formación paisajista y carecen del individualismo exagerado que padecemos.

Muchas veces la naturaleza les ha dado el parque antes que la ciudad, en tal caso su mérito ha sido mantener el verde y el arbolado, en lugar de talar los árboles y empeñarse en edificar hasta el último rincón, como es usual entre nosotros. Pero en otros casos, el suelo era roca árida y en tal circunstancia, para crear el medio verde de sus barrios, han traído la tierra y han plantado el parque.

No existe especulación sobre el suelo y a este efecto basta decir que el precio de un terreno en las afueras de una ciudad parece que al cambio no excede de cinco pesetas el metro cuadrado. Todos estamos convencidos de que hasta que se logre desterrar el cáncer de la especulación abusiva sobre el suelo, de esta ficción 
que es el agio de los terrenos, no podremos practicar un urbanismo de altura.

Por último, en cuanto a la dirección urbanística se refiere, no cabe duda de que es imposible el libertinaje a que estamos habituados, y ejemplo nos da un país que se titula demócrata, de que en orden al crecimiento de las ciudades, la democracia es el bien general y para lograrlo ha de haber un director que oriente tal crecimiento.

Manuel Baldrich Tibau 